\title{
Valkoapilan ja typpilannoituksen vaikutus laitumen kivennäiskoostumuk- seen ja karitsoiden kivennäisten saantiin
}

\author{
Päivi Nykänen-Kurki ${ }^{1}$, Riitta Sormunen-Cristian ${ }^{2}$, Lauri Jauhiainen ${ }^{3}$ ja Oiva Nissinen ${ }^{4}$ \\ MTT Maa- ja elintarviketalouden tutkimuskeskus \\ ${ }^{1}$ Ympäristöntutkimus, 50600 Mikkeli \\ ${ }^{2}$ Kotieläintuotannon tutkimus, 31600 Jokioinen \\ ${ }^{3}$ Tutkimuspalvelut, 31600 Jokioinen \\ ${ }^{4}$ Alueellinen yksikkö, 96900 Saarenkylä
}

\section{Tiivistelmä}

Valkoapilan vaikutusta laiduntavan eläimen kivennäisten saantiin on tutkittu huomattavasti vähemmän kuin sen vaikutusta rehun sulavuuteen ja valkuaispitoisuuteen. Karitsoiden valkoapila- ja heinälaidunkoetta jatkettiin analysoimalla laidunten kivennäiskoostumus ja karitsoiden kivennäisten saanti kolmen vuoden tutkimusjakson aikana. Heinälaitumia oli kolme. Ne saivat typpeä 0, 120 tai $250 \mathrm{~kg} \mathrm{ha}^{-1}$ vuodessa. Valkoapilaheinälaitumia oli yksi ja sitä ei lannoitettu typellä. Karitsat laidunsivat kaksi kolmesta viiteen viikon jaksoa kaikkien tutkimuskesien aikana.

Valkoapilalaitumen valkoapilapitoisuus oli ensimmäisellä laidunjaksolla keskimäärin 25 \% ja toisella 42 \%. Laidunrehun kivennäispitoisuus (Ca, Mg, P, K, Se ja N) ja laidunrehun nitraattipitoisuus määritettiin. Syönnin määrittämiseen käytettiin $n$-alkaaneja merkkiaineena, minkä pohjalta laskettiin karitsoiden kivennäisten saanti. Laitumen typpilannoituksen tehokkuutta arvioitiin kriittisen typpikäyrän avulla.

Valkoapilalaitumen laidunrehun kuiva-aineen kalsiumpitoisuus (7,8 vs 4,7 $\left.\mathrm{g} \mathrm{kg}^{-1}\right)$, magnesiumpitoisuus $\left(2,1\right.$ vs $\left.1,8 \mathrm{~g} \mathrm{~kg}^{-1}\right)$ ja $\mathrm{Ca} / \mathrm{P}$ suhde $(1,9$ vs 1,2$)$ olivat kaikki korkeampia kuin heinälaitumien. $\mathrm{K} /(\mathrm{Ca}+\mathrm{Mg})$-ekvivalenttisuhde $(1,7$ vs 2,5$)$ oli matalampi valkoapilalaitumessa kuin heinälaitumessa. Karitsoiden kalsiuminsaanti oli riittävä valkoapilalaitumella, mutta jäi 50 \%:iin tarpeesta heinälaitumilla. Kasvilaji ei vaikuttanut fosfori-, kalium- ja seleenipitoisuuksiin. Kaikilla laitumilla fosforinsaanti oli riittävä, kaliuminsaanti liian suuri ja seleeninsaanti liian pieni tarpeeseen nähden. Typpilannoitus lisäsi sekä kaliumin- (33,5 vs 38,5 $\left.\mathrm{g} \mathrm{kg}^{-1}\right)$ että seleeninottoa $\left(0,08\right.$ vs $\left.0,14 \mathrm{mg} \mathrm{kg}^{-1}\right)$ heinälaitumilla.

Kriittisen typpikäyrän avulla tarkasteltuna pääosassa laitumia typen niukkuus rajoitti laitumen kuiva-aineen tuotantoa. Muutamalla korkeimman typpilannoituksen saaneella heinälaitumella todettiin sadonmuodostuksen kannalta turhan korkea kasvuston typpipitoisuus. Tämä tarkoittaa, että kaikki kasvissa oleva typpi ei tule käytetyksi kuiva-aineen- ja valkuaisentuotantoon vaan kasviin alkaa kerääntyä nitraatteja. Näillä ruuduilla mitattiinkin karitsoille liian korkeita nitraattipitoisuuksia (>10 000 mg $\mathrm{kg}^{-1}$ ). Lisäksi karitsoilla ilmeni terveysongelmia samoilla ruuduilla. Seleeniä lukuun ottamatta valkoapilalaitumen kivennäiskoostumus oli karitsan kannalta heinälaidunta tasapainoisempi.

Avainsanat: kivennäiskoostumus, nitraatti, seleeni, Trifolium repens, typpi, valkoapilalaidun 


\section{Johdanto}

Nurmipalkokasveja käytetään laitumissa sekä laidunrehun maittavuuden lisäämiseen että tuotannon parantamiseen. Valkoapila tunnetaan erinomaisena rehukasvina hyvän sulavuutensa, korkean valkuaispitoisuutensa ja maittavuutensa vuoksi. Valkoapila kestää laidunnusta muita nurmipalkokasveja paremmin. Laidunnus kuitenkin muuttaa laidunkasvien morfologiaa, mikä yhdessä lannan kanssa vaikuttaa suoraan laidunrehun kivennäiskoostumukseen. Valkoapila-heinälaitumen kivennäiskoostumuksesta on olemassa melko niukasti tutkittua tietoa. Kolmivuotisen karitsoiden laidunhankkeen tuloksia (Sormunen-Cristian ym. 1996) täydennettiin määrittämällä valkoapilaheinä- ja heinälaitumien kivennäiskoostumus ja laskemalla karitsoiden kivennäisten saanti suhteessa tarpeeseen.

\section{Aineisto ja menetelmät}

Karitsoiden laidunkokeessa oli neljä laidunkäsittelyä: kolme heinälaidunta $(\mathrm{H})$ ja yksi valkoapilalaidun (VA). Heinälaitumien siemenseos sisälsi timoteita (lajike Iki) $3,5 \mathrm{~kg} \mathrm{ha}^{-1}$, englannin raiheinää (lajike Riikka) 6,0 $\mathrm{kg} \mathrm{ha}^{-1}$ ja nurminataa (lajike Kalevi) $9,0 \mathrm{~kg} \mathrm{ha}^{-1}$. Heinälaitumet saivat typpeä (N) $0 \mathrm{~kg} \mathrm{ha}^{-1}$ (H0), $120 \mathrm{~kg} \mathrm{ha}^{-1}$ (H120) tai $250 \mathrm{~kg} \mathrm{ha}^{-1}$ (H250). Laidunkäsittelyt arvottiin koekentälle satunnaistettujen lohkojen mallia käyttäen. Kerranteita oli neljä. Kunkin laidunkaistan koko oli 8 m * 80 m.

Valkoapilalaitumessa oli valkoapilaa lajikkeiden Sonja (25 \%) ja Jögeva 4 (75 \%) seosta 4 kg $\mathrm{ha}^{-1}$ ja seossuhteiltaan samaa heinäseosta kuin heinälaitumissa $12 \mathrm{~kg} \mathrm{ha}^{-1}$. Valkoapilalaidunta ei lannoitettu typellä. Koealueen maalaji oli multamaa, jonka pH oli 5,7 (tyydyttävä). Koealueen kalsiumluku (Ca $3991 \mathrm{mg} \mathrm{l}^{-1}$ maata) ja magnesiumluku (Mg $471 \mathrm{mg} \mathrm{l}^{-1}$ maata) olivat molemmat korkeita. Fosfori- (P 13,3 $\mathrm{mg} \mathrm{l}^{-1}$ maata) ja kaliumluvut (K $186 \mathrm{mg} \mathrm{l}^{-1}$ maata) olivat tyydyttäviä. Koe lannoitettiin 36 $\mathrm{kg} \mathrm{ha}^{-1} \mathrm{P}$ and $42 \mathrm{~kg} \mathrm{ha}^{-1} \mathrm{~K}$ toukokuussa. Karitsat laidunsivat kolmen - viiden viikon jaksoissa vuosina 1994-1996. Laidunjaksoja oli kaksi kunakin kesänä ja eläintiheys oli 62,5 lammasta ha"-1.

Laidunrehun botaaninen ja kemiallinen koostumus määritettiin kahden viikon välein laidunjaksojen aikana. Kokonaistyppi analysoitiin Kjeldahlin menetelmällä ja nitraattipitoisuus AKEAn FIAanalysaattorilla. Ca, P, Mg ja K määritettiin kaasukromatografilla. Seleeni (Se) määritettiin spektrofotometrisesti autoanalysaattorilla. Lampaiden syönti määritettiin $n$-alkaaneita merkkiaineena käyttäen (Mayes ym. 1986). Vuonna 1995 syönninmäärityskokeessa oli 16 lammasta ja seuraavana vuonna 32 lammasta. Syönnin määritys mahdollisti kivennäisten saannin laskemisen rehun kuiva-ainetta $\left(\mathrm{kg}^{-1} \mathrm{ka}\right)$ ja karitsoiden metaboolista elopainokiloa $\left(\mathrm{kgW}^{0.75}\right)^{-1}$ kohti. Typpilannoituksen tehokkuutta arvioitiin kriittisen typpikäyrän avulla (Lemaire \& Meynard, 1997). Kriittinen typpikäyrä osoittaa $\mathrm{C}_{3}$-kasvien kokonaistyppipitoisuutta suhteessa kuiva-aineen tuotantoon, kun typpilannoitus ei rajoita kasvua. Aineisto analysoitiin tilastollisesti SAS Instituutin GLM ohjelmistolla.

\section{Tulokset ja tulosten tarkastelu}

Kesän ensimmäisen laidunjakson valkoapilapitoisuus oli keskimäärin $25 \%$ ja toisen 42 \%. Kivennäiskoostumus vaihteli laidunten välillä (Taulukko 1). Sekä valkoapilalaitumen kuiva-aineen kalsium- (7,8 vs 4,7 $\left.\mathrm{g} \mathrm{kg}^{-1}\right)$ että magnesiumpitoisuus (2,1 vs 1,8 $\left.\mathrm{g} \mathrm{kg}^{-1}\right)$ oli korkeampi kuin heinälaitumien.

\section{Taulukko 1. Laidunrehun Ca, Mg, $P$ ja K ( $\left.\mathrm{g} \mathrm{kg}^{-1} \mathrm{ka}\right)$ sekä Se ja nitraattipitoisuus (mg kg-1 $\left.\mathrm{ka}\right)$.}

\begin{tabular}{|c|c|c|c|c|c|c|c|}
\hline & \multicolumn{4}{|c|}{ Estimaatti } & \multirow{2}{*}{$\begin{array}{r}\text { Keskiarvon } \\
\text { keskivirhe } \\
\end{array}$} & \multirow[t]{2}{*}{ P1 } & \multirow[t]{2}{*}{$\mathrm{P} 2$} \\
\hline & VA & $\mathrm{HO}$ & H120 & H250 & & & \\
\hline $\mathrm{Ca}$ & 7,80 & 5,10 & 4,60 & 5,00 & 0,55 & $* * *$ & \\
\hline $\mathrm{Mg}$ & 2,20 & 1,70 & 1,90 & 2,00 & 0,14 & $* * *$ & $* *$ \\
\hline $\mathrm{P}$ & 4,40 & 4,40 & 4,20 & 4,10 & 0,06 & ** & $* * *$ \\
\hline K & 39,00 & 36,00 & 38,00 & 40,00 & 0,60 & $*$ & $* * *$ \\
\hline Se & 0,07 & 0,06 & 0,09 & 0,09 & Aineisto- & $* *$ & $* * *$ \\
\hline Nitraatti & 3535,00 & 1205,00 & 3586,00 & 9370,00 & muunnos & & ** \\
\hline
\end{tabular}

P1 osoittaa valkoapila- ja heinälaidunten välistä eroa ja P2 typpilannoituksen lineaarista vaikutusta heinälaitumissa. VA = typpilannoittamaton valkoapilaheinälaidun. $\mathrm{H} 0=$ typpilannoittamaton heinälaidun. H120 = $120 \mathrm{~kg}$ ha $^{-1} \mathrm{~N}$ ja H250 = $250 \mathrm{~kg} \mathrm{ha}^{-1} \mathrm{~N}$ heinälaidun. 
Valkoapilalaitumen $\mathrm{Ca} / \mathrm{P}$-suhde $(1,9$ vs 1,2$)$ oli korkeampi ja $\mathrm{K} /(\mathrm{Ca}+\mathrm{Mg})$-ekvivalenttisuhde $(1,7$ vs 2,5) matalampi kuin heinälaitumien. Kasvaville lampaille suositeltava $\mathrm{Ca} / \mathrm{P}$-suhde on 1,8 (ARC, 1980). Heinälaitumien Ca/P suhde jäi edellä mainitun arvon alle, mutta valkoapilalaidun oli tässä suhteessa suosituksen mukainen karitsoille. Valkoapilalaitumen ja heinälaidunten fosfori-, kalium- ja seleenipitoisuudet eivät eronneet toisistaan. Fosforipitoisuus oli keskimäärin 4,0 $\mathrm{g} \mathrm{kg}^{-1} \mathrm{ka}$, kaliumpitoisuus 36,3 $\mathrm{g} \mathrm{kg}^{-1} \mathrm{ka}$ ja seleenipitoisuus $0,07 \mathrm{mg} \mathrm{kg}^{-1} \mathrm{ka}$. Sekä kalium- (33,5 vs 38,5 g kg $\mathrm{ka}^{-1}$ ) että seleenipitoisuus kasvoi typpilannoituksen kasvaessa (0.08 vs $0.14 \mathrm{mg} \mathrm{kg}^{-1} \mathrm{ka}$ ).

Kivennäisten saanti laskettiin syönnin arvioinnin pohjalta. Syönti oli valkoapilalaitumella keskimäärin $106 \mathrm{~g}$ ka $\left(\mathrm{kgW}^{0.75}\right)^{-1}$ ja heinälaitumilla $69 \mathrm{~g} \mathrm{ka}\left(\mathrm{kgW}^{0.75}\right)^{-1}$. Kasvavien lampaiden kalsiumin saanti oli valkoapilalaitumella riittävä, mutta ei liian korkea. Heinälaitumilla kalsiumin saanti oli noin 50 \% tarpeesta. Fosforin saanti oli riittävä, seleenin liian niukka ja kaliumin liian korkea kaikilla laitumilla. Tämä ei kuitenkaan aiheuttanut lampaille terveysongelmia.

Kasvien typensaantia voidaan arvioida kriittisen typpikäyrän avulla (Lemaire \& Meynard, 1997). Kriittinen typpikäyrä osoittaa kasvin kokonaistyppipitoisuuden suhdetta kuiva-aineen tuotantoon. Lemaire \& Meynard (1997) esittivät vakiomuodossa olevan funktion $\mathrm{C}_{3}$-kasveille, kun typpi ei rajoitta kasvua. Niin kauan kuin kasvin typpipitoisuus on käyrän alapuolella, typensaanti rajoittaa kuiva-aineen tuotantoa. Tällöin typpilannoitus lisäisi kuiva-ainesatoa. Jos kasvin typpipitoisuus on käyrän yläpuolella, typpeä on liikaa suhteessa kuiva-aineen tuotantoon. Kaikki kasvissa oleva typpi ei tule käytetyksi kuiva-aineen- ja valkuaisentuotantoon vaan kasviin alkaa kerääntyä nitraattia. Myös osa maassa liukoisessa muodossa olevasta typestä joutuu huuhtoutumisriskin alaiseksi. Kriittisen typpikäyrän perusteella voi todeta, että tässä esitetyssä laidunkokeessa typensaanti rajoitti useiden laidunten kasvua (Kuva 1).

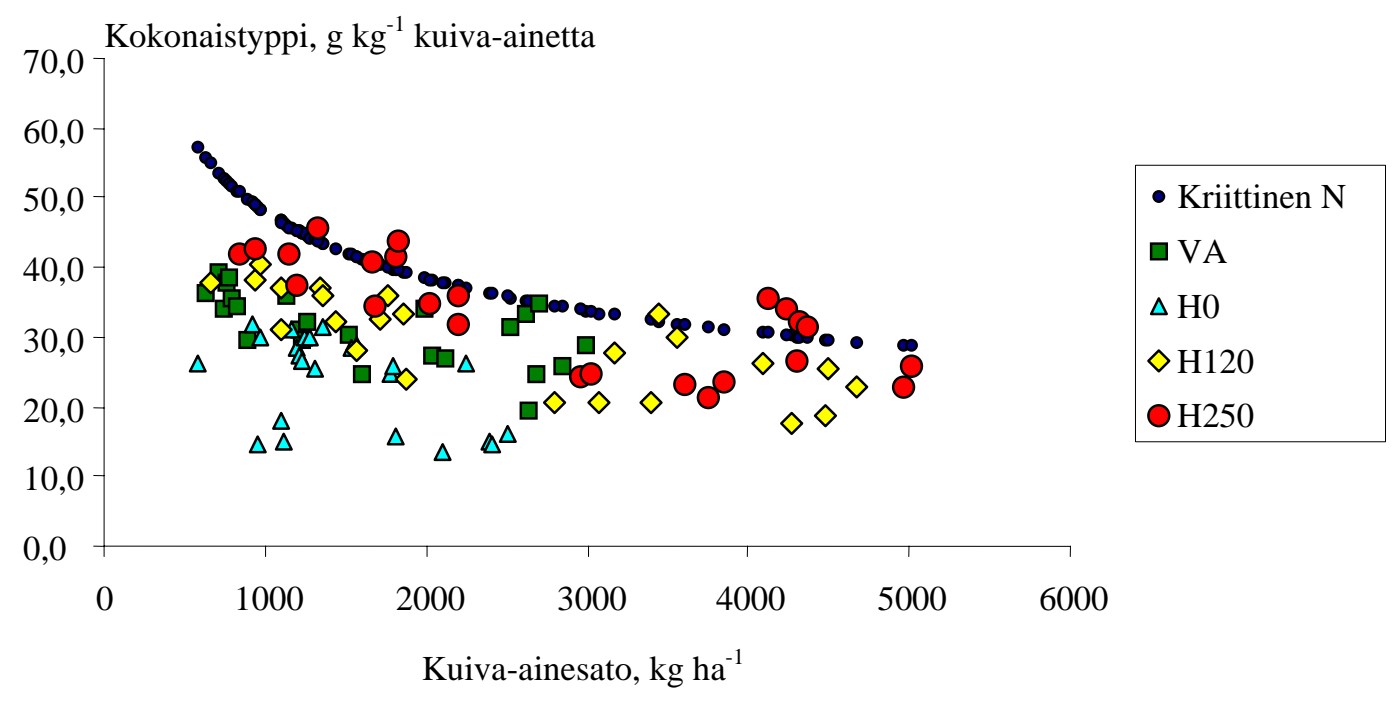

\section{Kuva 1. Laidunrehun kokonaistyppipitoisuus verrattuna kuiva-ainesadon muodostukseen.}

Laidunrehun kokonaistyppipitoisuus oli korkea eläinten kannalta katsottuna. Korkeimmat pitoisuudet mitattiin joillakin korkeimman typpilannoituksen heinälaitumilla. Samoilla ruuduilla mitattiin hyvin korkeita laidunrehun nitraattipitoisuuksia (>10 $000 \mathrm{mg} \mathrm{kg}^{-1} \mathrm{ka}$ ) ja niillä esiintyi myös yksittäisiä karitsoiden terveysongelmia. Niin ikään kokonaistyppipitoisuus oli näillä samoilla ruuduilla kriittisen typpikäyrän yläpuolella osoittaen liian korkeaa typpilannoitusta suhteessa laitumen kuiva-aineen tuotantoon.

\section{Johtopäätökset}

Seleeniä lukuun ottamatta valkoapilalaitumen kivennäiskoostumus oli lampaille heinälaitumia tasapainoisempi. Osa heinälaitumille annetusta lannoitetypestä meni hukkaan korkeimmalla typpitasolla. Liian korkea typpi aiheutti lampaille terveysriskin nitraatin kertymisenä laidunrehuun. Lampaiden terveys oli hyvä valkoapilalaitumella. 


\section{Kirjallisuus}

ARC 1980. The nutrient requirements of ruminant livestock. Technical review by an Agricultural Research Council working party. Commonwealth Agricultural Bureaux, Slough, England. 351 p.

Lemaire, G. \& Meynard, J. M. 1997. Use of the nitrogen nutrition index for the analysis of agronomical data.In: Lemaire, G. (Ed.) Diagnosis of the nitrogen status in crops. Berlin: Springer. Pp 45-55.

Mayes, R. W., Lamb, C. S. \& Colgrove, P. M. 1986. The use of dosed and herbage $n$-alkanes as markers for the determination of herbage intake. J. Agric. Sci., Cambridge 107: 161-170.

Sormunen-Cristian, R., Nykänen-Kurki, P. \& Peltola, J. 1996. On white clover based grazing of lamb pastures. Grassland Science in Europe 1: 625-628. 